\title{
The Future of Pulmonary Function Testing
}

\author{
Neil R MacIntyre MD FAARC
}

\author{
Introduction \\ What Needs to Be Done to Move Current Testing Procedures Into the \\ Future to Better Meet These Goals? \\ What New Procedures Available Today Hold Promise as Additions to the \\ Pulmonary Function Laboratory? \\ Respiratory System Mechanics \\ Pulmonary Gas Exchange \\ Noninvasive Cardiac Output \\ Analysis of Exhaled Biomarkers \\ What New Procedures in the Future Could Hold Promise as Additions to \\ the Pulmonary Function Laboratory? \\ Pulmonary Gas Exchange (Ventilation-Perfusion Matching) \\ Tissue Oxygen Delivery \\ Imaging \\ Advanced Exhaled Biomarker Analysis \\ Barriers to Implementation of New Technologies \\ Summary
}

\begin{abstract}
The pulmonary function lab of today is heavily focused on describing pathophysiology and quantifying the extent of disease. As we move forward, it is important that the results of pulmonary function tests go beyond this and be linked to important outcomes that truly affect clinical decision making. To get there, improvements in device performance are required, high quality technicians are critical, and properly trained interpreting clinicians with good reference standards are mandatory. Moreover, as accessibility to these tests is increased, it is important that quality metrics remain intact. There is a wide array of novel tests that might be performed by pulmonary function labs in the future. These range from modification of current technologies to brand new technologies that are still in early development. Examples include exhaled breath analysis, sophisticated analyses of lung mechanics and gas exchange, cardiac and tissue oxygenation assessments, and imaging technologies. Adoption of any new technology will require, even more than today, clear evidence that the new technology is a real adjunct to clinical decision making. Key words: pulmonary function testing; PFT. [Respir Care 2012;57(1):154-161. ( 2012 Daedalus Enterprises]
\end{abstract}

Neil R MacIntyre MD FAARC is affiliated with the Division of Pulmonary and Critical Care Medicine, Duke University Medical Center, Durham, North Carolina.

Dr MacIntyre presented a version of this paper at the 48th RESPIRATORY CARE Journal Conference, "Pulmonary Function Testing," held March 2527, 2011, in Tampa, Florida.
Dr MacIntyre has disclosed a relationship with CareFusion.

Correspondence: Neil R MacIntyre MD FAARC, Division of Pulmonary and Critical Care Medicine, Duke University Hospital, Box 3911, Durham NC 27710. E-mail: neil.macintyre@ duke.edu.

DOI: $10.4187 /$ respcare. 01422 


\section{Introduction}

On the surface, pulmonary function testing has 2 purposes. First, pulmonary function tests are designed to put patients into clinical/physiologic "buckets"1,2 (Fig. 1). These buckets include the obstructive diseases (asthma, bronchitis, emphysema), the restrictive diseases (intrapulmonary and extrapulmonary processes), the neuromuscular diseases, and the vascular diseases. The second goal of pulmonary function testing is to quantify the severity of a physiologic derangement. ${ }^{3}$ Usually this requires comparing the measured value to a predicted or reference value, but the actual quantification is often done in a somewhat arbitrary fashion. An example of this is the Global Initiative for Chronic Obstructive Lung Disease (GOLD) criteria for grading severity of airway obstruction, in which patients are broken down into groups of percent of predicted values for $\mathrm{FEV}_{1}$ (ie, > 80\%, 50-79\%, 30-49\%, and $<30 \%){ }^{4}$ These grading strategies are based on convenient mathematical subdivisions and not really on any functional or outcome effects.

Pulmonary function testing, however, should not be limited to just defining buckets and quantifying severity of the derangement. Those are simply descriptive functions. The ultimate goal would be to use these tests to predict important outcomes. Examples include assessing and predicting quality of life, functional capabilities, future morbidity/ mortality, and the risk/benefit of an intervention. ${ }^{5-11} \mathrm{Un}$ fortunately, at the present time the role of pulmonary function testing remains heavily focused on "buckets" and arbitrary severity grading systems. The future pulmonary function laboratory and the development of future pulmo-

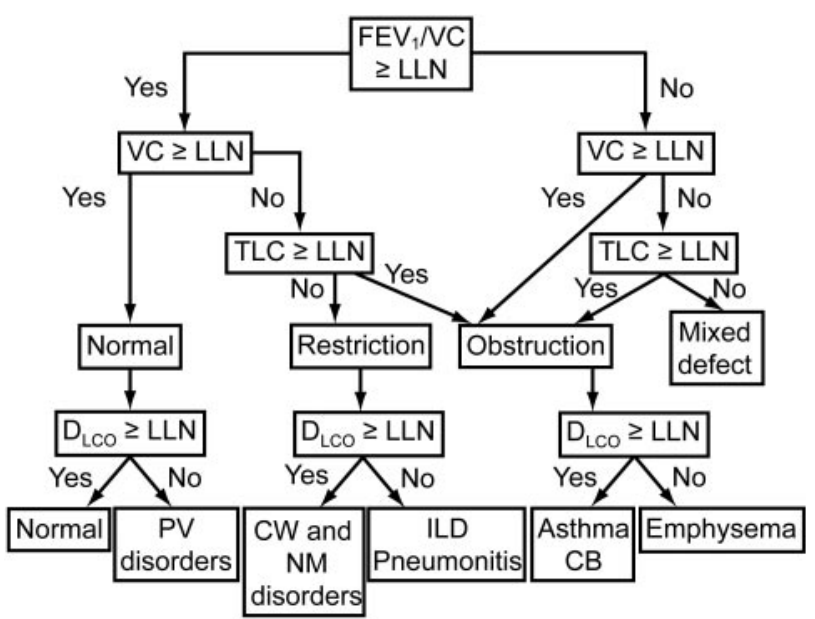

Fig. 1. The concept of using pulmonary function tests to place subjects into physiologic "buckets" using the interpretation algorithm of the American Thoracic Society/European Respiratory Society task force. $\mathrm{VC}=$ vital capacity. $\mathrm{LLN}=$ lower limit of normal. $\mathrm{PV}=$ pulmonary vascular. $\mathrm{CW}=$ chest wall. $\mathrm{NM}=$ neuromuscular. $\mathrm{CB}=$ chronic bronchitis. (From Reference 1, with permission.) nary function tests need to be developed with a focus on integrating test results into the clinical decision making process. This approach would make pulmonary function testing and interpretation more akin to modern radiology and pathology services. Both of these services involve patient testing with professional interpretations that include careful descriptions of normal and abnormal findings. However, the ultimate interpretations from these services usually go on to link findings to specific diagnoses, risks, and outcomes. Moreover, they often also add clinical decision suggestions. This is what pulmonary function testing needs to strive for both in improving current procedures as well as in the development of new procedures.

\section{What Needs to Be Done to Move Current Testing Procedures Into the Future to Better Meet These Goals?}

As addressed in many other discussions during this conference, technical improvements are clearly needed to reduce variability and improve accuracy. This is true both for equipment performance as well as for operator performance. ${ }^{12-15}$ Inter- and intra-laboratory variability is still at unacceptably high levels, especially for tests that involve patient cooperation (eg, spirometry, plethysmographic functional residual capacity determinations) and devices with complex valving/sensing operations (eg, diffusing capacity). Equipment manufacturers have been shown to respond to calls from professional societies to meet certain technical standards. ${ }^{16}$ Equal emphasis needs to be placed on assuring operator skill standards. Making equipment as straightforward as possible to operate is only part of the solution here. The reliability and accuracy of these tests demand operators who are properly trained and skilled at these procedures. Moreover, this skill involves not only equipment operating skills but also patient interactive skills to assure proper effort. An office receptionist doubling as the office pulmonary function technician performing only 1 to 2 tests per week is not acceptable.

Many authorities are calling for formal certification programs to address these issues. Personnel certification programs such as the American Association for Respiratory Care "spirometry driver's license" and voluntary laboratory standards adherence programs such as the American Thoracic Society Pulmonary Function Laboratory Registry are a start in this direction. However, the development of a comprehensive laboratory certification process is still in its infancy in the United States, although it has progressed in other countries such as New Zealand and Canada. As these processes move forward, the focus must be on true performance-based certification of technologists, along with formal accreditation programs for laboratories. As payers increasingly demand high quality and cost-ef- 
fective diagnostics, it is almost a certainty that formal programs to assure quality are going to appear.

The process of interpreting test results also needs considerable improvement. As has also been discussed at this conference, appropriate reference values are critical in order to determine whether a patient is normal, abnormal, or in a particular risk category. ${ }^{17-19}$ It is clearly unacceptable that a patient can move from being considered "normal" to being substantially "at risk" by simply changing reference equations. ${ }^{20}$ Population studies with subjects free of disease and without comorbidities and who are similar in race/ethnicity to the patients being tested are critical to have. Moreover, these population studies need to be sufficiently large with representation from a wide range of body sizes and age, so as to minimize reference value confidence intervals. Even with this, it is still appropriate for individual laboratories to perform testing in a sample of 50-100 normal subjects from the community being served to assure that the most applicable reference equations are being used.

The actual interpreter needs not only to understand respiratory system pathophysiology, but also must be capable of recognizing patient effort issues and technical errors. This calls into question the assumption that any physician can properly interpret these tests-an assumption that has been seriously challenged in several large trials of general practitioner performance in assessing pulmonary function tests. ${ }^{21}$ It also calls into question the notion that computers can be programmed to do useful test interpretations. While this is no doubt true for straightforward patterns of lung abnormalities in cooperative patients, computer interpretation programs that are capable of assessing complex flow patterns, patient cooperation effects, or in integrating test results into a comprehensive patient assessment have yet to be developed. At present, then, computers are better suited as a source of preliminary suggestions, and not the final word.

Indeed, quality interpretation today and into the foreseeable future needs clinicians who are properly trained in all aspects of pulmonary physiology and testing. Unfortunately, formal in-depth pulmonary fellowship training in these skills is all too often being sacrificed because of limited duty hours and the need for training in so many other new procedures. Moreover, in many hospitals there is no formal credentialing for pulmonary function interpretation-a decision often driven by broad revenue demands rather than by concerns for effective test interpretation.

As noted above, interpretation should not stop at simply accurately describing any abnormalities that are present. For pulmonary function laboratories to really increase in value in the future, interpretations need to be integrated into patient decision making. The request for testing should not be simply to "evaluate function." Instead it should include specific questions about risks/benefits, effects of a planned or ongoing intervention, or prognosis. To this end, the approach of using pre- and post-test probabilities to interpret a result has considerable merit.

For this progress to occur, studies are clearly needed to actually link the results of a test with a functional abnormalities and/or an important outcome. Although pulmonary function tests have been shown for decades to correlate with many things, such as exacerbations in COPD, quality of life, risk of surgical procedures, and even mortality, ${ }^{5-11}$ at present these pulmonary function test results often lack sufficient discriminatory power to be really helpful in individual patient decision making. An example would be that while abnormal spirometric results suggest a high postoperative risk for pulmonary complications, rarely does a spirometric abnormality actually change the decision to perform surgery. ${ }^{8}$ Similarly, while the carbon monoxide diffusing capacity is a useful marker for druginduced lung injury, it has not been shown to be a good enough predictor of drug toxicity risk to affect the decision to initiate a drug. The reasons for this lack of discriminatory power are multi-factorial but include the fact that pulmonary function tests have a considerable variability, that patients often have comorbidities that affect test results and outcomes, and that a single physiologic test reflects only a single aspect of function, which needs to be integrated with the entire clinical picture.

Although perhaps a bit mundane, another problem in limiting current pulmonary function testing utility is turnaround time. This was illustrated by a recent American Thoracic Society Pulmonary Function Laboratory Registry survey demonstrating that the average turnaround time from testing to report generation was 3 to 4 days and that much of this can be traced to the fact that many laboratory interpretation strategies still rely heavily on things like dictation and hand-written notes. ${ }^{22} \mathrm{~A}$ test result and its interpretation cannot be acted upon until it is communicated to the referring clinician.

Finally, the future pulmonary function laboratory needs to be more accessible to those who need it. Underscoring this need is the fact that in one study, the majority of hospitalized patients labeled as "COPD" had not had spirometric testing to confirm and stage the disease. ${ }^{23}$ Substantial barriers to expanded accessibility, of course, are equipment costs and reimbursement issues. Perhaps more important is the need to make sure that as laboratories expand to serve more patients, quality remains intact. ${ }^{24}$ Even if done properly, however, expanded testing can be a two-edged sword. There certainly are benefits to finding abnormalities in patients in whom changes can be instituted. But there is also the harm of false positives (unnecessary further testing or risky procedures) and false negatives (a missed diagnosis preventing further action) from even the best of testing. False negatives can be minimized 
by maintaining the highest possible quality. While this is also true for minimizing false positives, if service expansion results in larger and more low risk populations being tested (ie, broad "screening"), the number of false positives will dramatically increase and, indeed, the number of false positives can overwhelm the number of true positives. ${ }^{25}$ As accessibility is expanded, it needs to be clearly shown that increased diagnostic capabilities truly lead to improved outcomes.

\section{What New Procedures Available Today Hold Promise as Additions to the Pulmonary Function Laboratory?}

There are a number of novel devices that assess various aspects of pulmonary function that have been released to market over the last several decades. None of these are in widespread use, but each has some attractive features that could eventually result in the test becoming mainstream. These are grouped below into technologies that assess respiratory system mechanics, pulmonary gas exchange, noninvasive cardiac output, and exhaled biomarkers.

\section{Respiratory System Mechanics}

There are several interesting novel approaches to assessing respiratory system mechanical function. Probably the most widely studied is the used of forced pressure oscillations applied to the open airway. Sophisticated analyses of the pressure and flow signal as the oscillations are delivered and reflected back to the device can give unique insight into airway resistance and reactance. ${ }^{26}$ These signals address properties of airways that the simple measures of exhaled flow cannot. Indeed, this technique is probably complementary to spirometry in that large airway and small airway function can be separated during rest, exercise, and after exposure to an airway challenge. It may also help in evaluating the interactions of applied PEEP and intrinsic PEEP in subjects with airway obstruction. Because this technique has the capability of measuring mechanics during simple tidal breathing, it thus offers advantages in patients unable to cooperate with spirometry (eg, children).

Another novel approach to assessing respiratory system mechanics is the use of an esophageal balloon to estimate pleural pressures. ${ }^{27}$ This technique requires insertion of an air-filled balloon into the mid-esophagus and then measuring pressures during various breathing maneuvers. Measurement of esophageal pressure permits the separation of chest wall/abdominal compliance properties from actual lung compliance. This can be helpful especially in patients with such things as ascites, obesity, chest wall deformities, and anasarca, which can have profound effects on the work of breathing. Respiratory muscle strength capabili- ties, which are often estimated by the use of mouth pressures developed against a closed shutter, can be directly measured by the esophageal balloon. ${ }^{28}$

\section{Pulmonary Gas Exchange}

The gold standard for assessing pulmonary gas exchange is direct analysis of arterial blood. As this requires an invasive arterial puncture, a rapidly growing field involves the development of devices to assess blood gas parameters using noninvasive technology. Certainly pulse oximetry has become commonplace as an estimate of hemoglobinoxygen saturation, and expanded pulse oximetry capabilities now include carboxyhemoglobin and total hemoglobin. ${ }^{29}$ Pulse oximetry, however, cannot measure the partial pressure of either oxygen or carbon dioxide, and this noninvasive need is being addressed by the development of transcutaneous technology. Although accuracy/reproducibility of this technology is heavily affected by capillary perfusion and distance from the sensor, reasonable estimates of $\mathrm{P}_{\mathrm{CO}_{2}}$ (and to a lesser extent $\mathrm{P}_{\mathrm{O}_{2}}$ ) can be obtained. ${ }^{30}$ These devices have found particular applicability in assessing regions of ischemia around wounds or surgical sites. They have also been useful in neonatal/pediatric intensive care units (ICUs), where skin barriers are thin. Their role in adult ICUs or pulmonary function (especially exercise) laboratories is less clear, but could become significant as technology improves.

Carbon monoxide uptake $\left(D_{\mathrm{LCO}}\right)$ from alveolar gas during a breath-hold has traditionally been used to measure alveolar capillary gas transport. ${ }^{15}$ Newer devices with rapid, real time gas analysis properties now allow $\mathrm{D}_{\mathrm{LCO}}$ to be measured with brief maneuvers during exercise, a measurement that reflects capillary "recruitability" (Figs. 2 and 3) and that therefore could be an earlier marker of pulmonary capillary dysfunction. ${ }^{31,32}$ Nitric oxide uptake from alveolar gas during a breath-hold $\left(\mathrm{D}_{\mathrm{LNO}}\right)$ could be complementary to $\mathrm{D}_{\mathrm{LCO}}$. Uptake of both of these gases is conceptually divided into the membrane transfer properties and the binding properties of the gas to hemoglobin. With NO, however, hemoglobin binding is many times faster than hemoglobin-CO binding, and thus the $\mathrm{D}_{\mathrm{LNO}}$ reflects primarily the membrane barrier to gas exchange. ${ }^{33}$ The clinical utility of separating membrane and hemoglobin binding aspects of gas exchange needs further study.

\section{Noninvasive Cardiac Output}

Measuring cardiac output is critical in fully evaluating the cardio-respiratory system, but its accurate determination has generally required invasive devices placed in the right heart/pulmonary artery. Technologies to noninvasively measure cardiac output (and sometimes lung water) have been developed for both critical care settings as well 


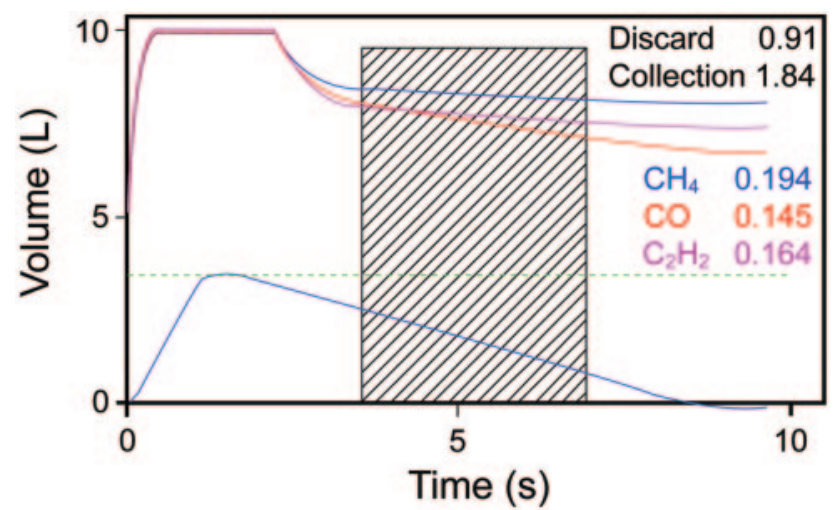

Fig. 2. The use of a real time analyzer during a single brief inhalation-exhalation of methane $\left(\mathrm{CH}_{4}\right)$, acetylene $\left(\mathrm{C}_{2} \mathrm{H}_{2}\right)$, and carbon monoxide (CO). The three gas concentrations are in the upper panel $\left(\mathrm{CH}_{4}\right.$ on top, $\mathrm{C}_{2} \mathrm{H}_{2}$ in the middle, and $\mathrm{CO}$ on the bottom), lung volume is in the lower panel, and data are plotted over time. Alveolar volume is calculated from $\mathrm{CH}_{4}$ dilution, pulmonary capillary blood flow from $\mathrm{C}_{2} \mathrm{H}_{2}$ uptake, and diffusing capacity from $\mathrm{CO}$ uptake.

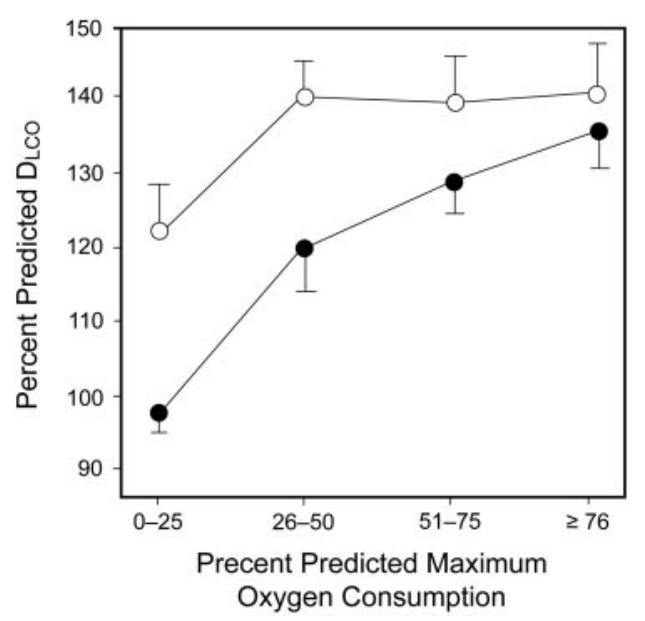

Fig. 3. Measuring $C O$ uptake ( $\left.D_{\text {LCO }}\right)$ under upright (closed circles) and supine (open circles) positions at rest and moderate exercise. Note that moderate exercise increases $D_{\text {LCO }}$ approximately $30 \%$ in the upright position, and this can be taken as a reflection of alveolar capillary recruitability from an increased cardiac output. Similar effects can be demonstrated when the subject is placed supine (increased cardiac output and less gravitational effects on the vertical distribution of pulmonary capillary blood volume). (From Reference 31, with permission.)

as diagnostic (especially exercise) laboratories. Current approaches include $\mathrm{CO}_{2}$ rebreathing analysis, impedance cardiography, soluble gas uptake during a brief breathhold (see Fig. 2, $\mathrm{C}_{2} \mathrm{H}_{2}$ signal) or rebreathing, and noninvasive pulse pressure analysis. ${ }^{34}$ While offering reasonably accurate assessments, each of these techniques has important limitations and generally requires expensive equipment and/or a high level of technical skill to perform. Nevertheless, this area of product development could have

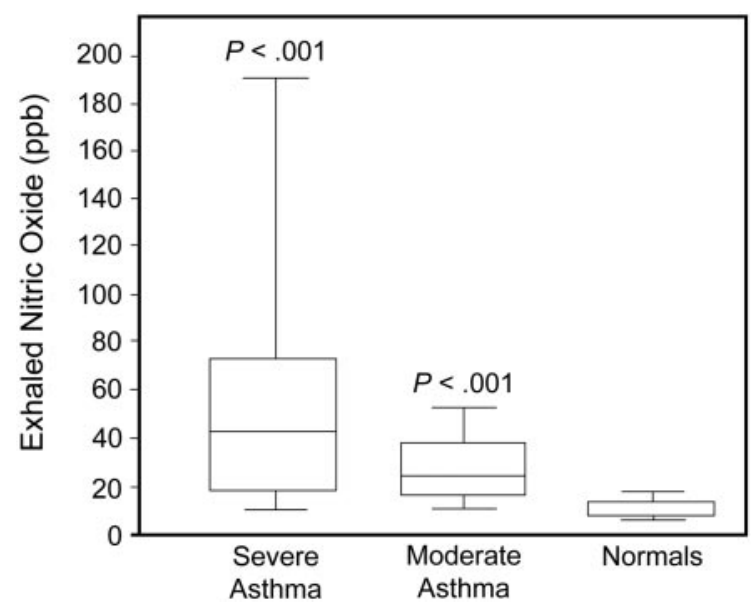

Fig. 4. The exhaled biomarker nitric oxide (NO) in subjects with airway inflammation and in normal subjects. Higher exhaled NO concentrations seem to be a marker for inflammation. (From Reference 36 , with permission.)

real clinical applicability as devices become less expensive, reliable, and easy to use.

\section{Analysis of Exhaled Biomarkers}

Analyses of exhaled biomarkers are just beginning to be developed for clinical use. These are noninvasive measurements of biologically active substances either produced by the body (eg, carbon dioxide, nitric oxide) or else absorbed by the body and then subsequently exhaled (eg, ethanol). These analyses are generally of 2 types: analysis of exhaled gases, or analysis of condensates of exhaled droplets of epithelial lining fluid (exhaled breath condensates [EBCs]). ${ }^{35-37}$ At present, in addition to the traditional measurements of exhaled oxygen, nitrogen, and carbon dioxide gases, analysis of exhaled nitric oxide (NO) is the only exhaled biomarker approved for clinical use. Elevation of exhaled NO is thought to be a marker of airway inflammation, especially in asthma but also in other airway diseases ${ }^{35-37}$ (Fig. 4). Algorithms have been proposed that incorporate this measurement as a tool to adjust medications in asthma and COPD. 36,37 The field of analyzing exhaled biomarkers is expanding rapidly, and newer approaches are described in more detail in the next section. The ability to perform these types of analyses could provide a real opportunity for the pulmonary function laboratory of the future.

\section{What New Procedures in the Future \\ Could Hold Promise as Additions to the Pulmonary Function Laboratory?}

As we look further into the future, there are several avenues of research and development that could emerge 
into clinical tests offered by the pulmonary function laboratory. These are grouped below into technologies that assess pulmonary gas exchange (ventilation-perfusion matching), tissue oxygen delivery, lung imaging capabilities, and advanced exhaled biomarkers.

\section{Pulmonary Gas Exchange (Ventilation-Perfusion Matching)}

Rather than simply measuring gas partial pressures and hemoglobin saturations of blood entering and leaving the lung, an interesting technique describes ventilation-perfusion relationships throughout the lungs. Known as the multiple inert gas elimination technique (MIGET), the procedure involves infusing a solution containing 6 gases of different solubilities and then measuring their elimination in alveolar gas. From this analysis, a 50-unit lung model is constructed representing the distribution of perfusion and ventilation to lung units with ventilation-perfusion relationships ranging from zero (shunt) to infinity (dead space). ${ }^{38}$ Conceptually, this has the potential to characterize all lung diseases into important physiologic phenotypes. At the present time, the technique requires complex equipment, skilled operators, and the infusion of a solution. If (and it is a big if) clinical utility is shown, simpler systems would likely follow.

\section{Tissue Oxygen Delivery}

The ultimate goal of the cardiorespiratory system is to deliver oxygen to the tissues. At present this is approximated by measuring oxygen content being delivered through the arterial system and oxygen content returning through the venous system. A novel approach is the use of near infrared spectroscopy to assess tissue cytochrome reduction/oxygenation status. This approach conceptually measures the "bottom line"- the actual entry of oxygen into the cytochrome system to generate ATP in important organs such as the brain. ${ }^{39}$ An additional attractive feature is that the device is entirely noninvasive. Reliable, reproducible signal processing with minimal artifact interference is still a challenge, and the expense can be considerable. Nevertheless, a technology that goes straight to tissue physiology could have real impact.

\section{Imaging}

Traditionally, imaging has been the purview of radiology departments. However, clever technologies free of radiation may become reasonable for use in pulmonary function laboratories, much like echocardiography has become a mainstay in cardiology department diagnostic laboratories. One such approach is acoustical imaging using an array of microphones over the chest to detect regional lung sounds. ${ }^{40,41}$ Underlying consolidation, airway obstruction, atelectasis, et cetera could then be mapped in an image-like format. Another noninvasive imaging technique that might appear in the future pulmonary function laboratory is the use of electrical impedance tomography. This utilizes electrocardiogram electrodes taped around the chest. Images of gas-filled and ventilated regions can then be constructed using a computer analysis of the electrical impedance across these various electrodes. ${ }^{42}$ This has been more extensively studied in ICU settings, but its placement in the pulmonary function lab could allow an assessment of regional lung function in non-ICU patients.

\section{Advanced Exhaled Biomarker Analysis}

The growing use of exhaled biomarker analysis described above is likely to be a major focus of the future pulmonary function laboratory. ${ }^{35-37}$ Exhaled gases contain not only the commonly appreciated physiologic gases noted above, but also contain thousands of volatile organic compounds that can reflect a variety of cellular functions in both normal and pathologic states. These compounds can range from simple hydrocarbons to complex chemical vapors, and have been linked to inflammation, infection, metabolic derangements, and neoplasms. ${ }^{35-37,43-45}$ Measurements of these compounds can be challenging, as they are often present in very low concentrations and are often also present in ambient air. Another aspect of exhaled gas analysis is temperature assessment, with warmth being associated with inflammation.

Exhaled biomarkers can also be analyzed in condensates of exhaled epithelial lining fluid droplets. ${ }^{35-37,43-45}$ As with exhaled gas analysis, a wide range of substances have been described in these condensates, and range from simple electrolytes (including hydrogen ion) to complex proteins involved in a variety of biochemical processes such as inflammation, tumor growth, oxidative stress, and infection. There are important technical issues to be worked out before these exhaled breath condensates can become routine clinical tests. These include important dilutional effects of the evaporated water, nonstandard analyses being performed, effects of the ventilator pattern, salivary contamination, and the fact that some of these substances have volatility that will affect their ultimate concentration in the analytic devices. ${ }^{46}$ Nevertheless, as these analyses become standardized and their links to various disease processes become clearer, they are likely to be an important addition to pulmonary diagnostic tests in the future (Fig. 5).

\section{Barriers to Implementation of New Technologies}

Barriers to implementation of new techniques are many. First, reliable devices have to be built that are inexpensive 


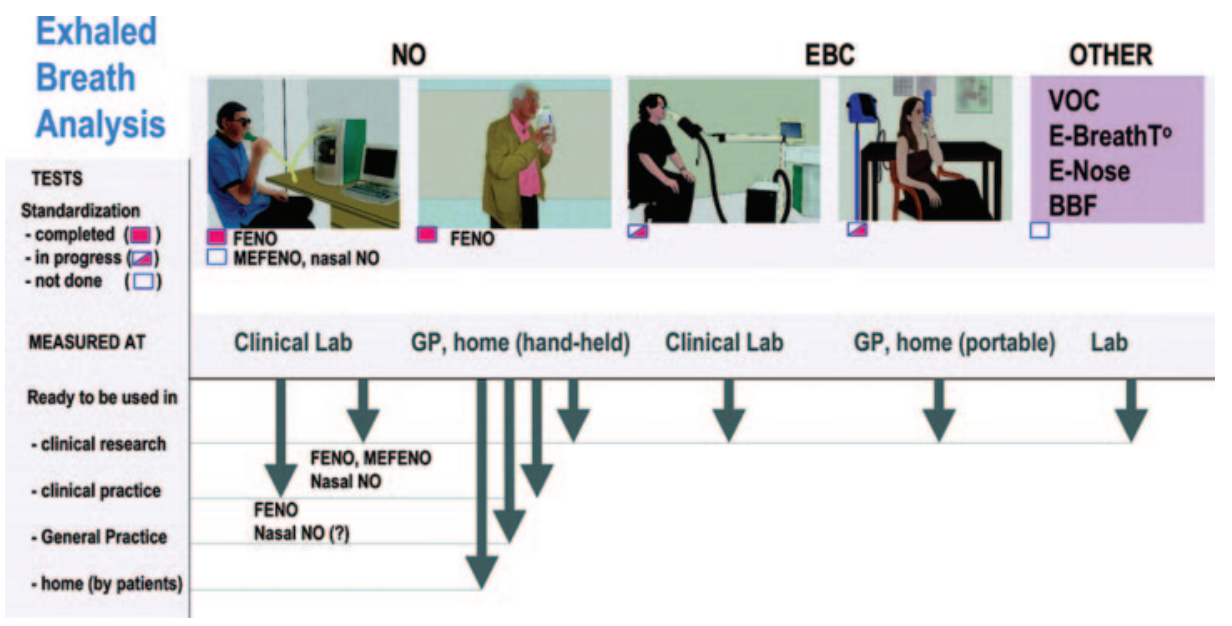

Fig. 5. Current status of exhaled biomarkers. EBC = exhaled breath condensate. GP = general practice. FENO = fraction of exhaled nitric oxide. MEFENO = multiple exhalation flow NO. VOC = volatile organic compounds. E-BreathT = exhaled breath temperature. E-Nose $=$ electronic nose type of breath analysis. BBF = bronchial blood flow. (From Reference 35, with permission.)

and relatively easy to use. Good technical training is going to be critical to assure accurate and reliable results. As noted above, before these devices are adapted clinically it is going to be critically important to prove that they are related to important outcomes and that they truly affect decision making on the part of clinicians. And of course, getting it paid for is a major hurdle for any new technique to overcome. This will require getting Current Procedural Terminology (CPT) codes with clear indications and clinical scenarios. The next step is convincing clinicians that data exist showing that this test is linked to outcomes and thus should impact decision making. Finally third-party payers must be convinced of a favorable cost/benefit ratio (ie, the improved outcomes are worth the cost).

\section{Summary}

The pulmonary function lab of the future needs to go beyond simply describing physiologic buckets and quantifying the extent of disease. It is absolutely critical that the results of pulmonary function tests be linked to important outcomes and truly affect clinical decision making. To get there, current labs need to have maximum accuracy and reliability of their devices, high quality technicians performing these tests, and high quality clinicians interpreting the tests using appropriate reference standards. As accessibility to these tests is increased, it is important that these quality metrics remain intact. There is a wide array of future tests that might be performed by pulmonary function labs in the future. These range from modification of current technologies to brand new technologies such as exhaled breath analysis, sophisticated analyses of lung mechanics and gas exchange, cardiac and tissue oxygenation assessments, imaging technologies, as well as others. The future of the pulmonary function laboratory is bright. Nevertheless, a constant striving for technical and interpretive excellence along with careful evidence-based studies linking these tests to outcomes is going to be critical to maintain this brightness.

\section{REFERENCES}

1. Pellegrino R, Viegi G, Brusasco V, Crapo RO, Burgos F, Casaburi $\mathrm{R}$, Coates A, et al. Interpretative strategies for lung function tests. Eur Respir J 2005;26(5):948-968.

2. Miller MR, Crapo R, Hankinson J, Brusasco V, Burgos F, Casaburi R, Coates A, et al; ATS/ERS Task Force. General considerations for lung function testing. Eur Respir J 2005;26(1):153-161.

3. American Thoracic Society. Evaluation of impairment/disability secondary to respiratory disorders. Am Rev Respir Dis 1986;133:12051209.

4. Global Initiative for Chronic Obstructive Lung Disease. Guidelines and resources. http://www.goldcopd.org/Guidelines/guidelinesresources.html. Accessed November 2, 2011.

5. Mannino DM, Buist AS, Petty TL, Enright PL, Redd SC. Lung function and mortality in the United States: data from the first National Health and Nutrition Examination Survey follow-up. Thorax 2003;58(5):388-393.

6. Celli BR. Predictors of mortality in COPD. Respir Med 2010;104(6): 773-779.

7. Neas LM, Schwartz J. Pulmonary function levels as predictors of mortality in a national sample of US adults. Am J Epidemiol 1998; 147(11):1011-1018.

8. Smetana GW, Lawrence VA, Cornell JE. Preoperative pulmonary risk stratification for noncardiothoracic surgery: systematic review for the American College of Physicians. Ann Int Med 2006;144(8): 581-595.

9. Miller JI. Physiologic evaluation of pulmonary function in the candidate for lung resection. J Thorac Cardiovasc Surg 1993;105(2): 347-351.

10. Collard HR, King TE Jr, Bartelson BB, Vourlekis JS, Schwarz MI, Brown KK. Changes in clinical and physiological variables predict survival in pulmonary fibrosis. Am J Respir Crit Care Med 2003; 168(5):538-542. 


\section{The Future of Pulmonary Function Testing}

11. Berry CE. Wise RA. Mortality in COPD: causes, risk factors, and prevention. J COPD 2010;7(5):375-382.

12. Kangalee KM, Abboud RT. Interlaboratory and intralaboratory variability in pulmonary function testing: a 13 year study using a normal biologic control. Chest 1992;101(1):88-92.

13. Miller MR, Hankinson J, Brusasco V, Burgos F, Casaburi R, Coates A, Crapo R, et al; ATS/ERS Task Force. Standardisation of spirometry. Eur Respir J 2005;26(2):319-338.

14. Wanger J, Clausen JL, Coates A, Pedersen OF, Brusasco V, Burgos $\mathrm{F}$, et al. Standardisation of the measurement of lung volumes. Eur Respir J 2005;26(3):511-522.

15. MacIntyre NR, Crapo RO, Viegi G, Johnson DC, van der Grinten $\mathrm{CP}$, Brusasco V, et al. Standardisation of the single-breath determination of carbon monoxide uptake in the lung. Eur Respir J 2005; 26(4):720-735.

16. Crapo RO. Jensen RL. Standards and interpretive issues in lung function testing. Respir Care 2003;48(8):764-772.

17. American Thoracic Society. Lung function testing: selection of reference values and interpretative strategies. Am Rev Respir Dis 1991; 144(5):1202-1218.

18. Jensen RL, Crapo RO, Flint AK, et al. Problems in selecting representative reference values for spirometry (abstract). Am J Respir Crit Care Med 2002;165:A200.

19. Jensen RL, Teeter JG, England RD, Howell HM, White HJ, Pickering EH, Crapo RO. Sources of long-term variability in measurements of lung function: implications for interpretation and clinical trial design. Chest 2007;132(2):396-402.

20. Collen J, Greenburg D, Holley A, King CS, Hnatiuk O. Discordance in spirometric interpretations using three commonly used reference equations vs national health and nutrition examination study III. Chest 2008;134(5):1009-1016.

21. White P, Wong W, Fleming T, Gray B. Primary care spirometry: test quality and the feasibility and usefulness of specialist reporting. Brit J Gen Pract 2007;57(542):701-705.

22. Davies J, Crapo RO, MacIntyre NR; ATS Pulmonary Function Laboratory Registry. Pulmonary function testing interpretation and report generation is a slow, cumbersome, and inefficient process (abstract). Respir Care 2005;50(11).

23. Damarla M, Celli BR, Mullerova Hx, et al. Discrepancy in the use of confirmatory tests in patients hospitalized with the diagnosis of chronic obstructive pulmonary disease or congestive heart failure. Respir Care 2006;51:1120-1124

24. MacIntyre NR, Selecky PA. Is there a role for screening spirometry? Respir Care 2010;55(1):35-40.

25. Vedal S, Crapo RO. False positive rates of multiple pulmonary function tests in healthy subjects. Bull Eur Physiopathol Respir 1983; 19(3):263-266

26. Hall GL, Sly PD, Fukushima T, Kusel MM, Franklin PJ, Horak F Jr, et al. Respiratory function in healthy young children using forced oscillations. Thorax 2007;62(6):521-526.

27. Boros PW, Enright PL, Quanjer PH, Borsboom GJ, Wesolowski SP, Hyatt RE. Impaired lung compliance and $\mathrm{D}_{\mathrm{LCO}}$ but no restrictive ventilator defect in sarcoidosis. Eur Respir J 2010;36(6):1315-1322.
28. Hayot M, Ramonatxo M, Matecki S, Milic-Emili J, Prefaut C. Noninvasive assessment of inspiratory muscle function during exercise. Am J Respir Crit Care Med 2000;162(6):2201-2207.

29. Barker SJ, Badal JJ. The measurement of dyshemoglobins and total hemoglobin by pulse oximetry. Curr Opin Anaesth 2008;21(6):805-810.

30. Nishiguchi BK, Yu M, Suetsugu A, Jiang C, Takiguchi SA, Takanishi DM Jr. Determination of reference ranges for transcutaneous oxygen and carbon dioxide tension and the oxygen challenge test in healthy and morbidly obese subjects. J Surg Res 2008;150(2):204-211.

31. Stokes DL, MacIntyre NR, Nadel JA. Nonlinear increases in diffusing capacity during exercise in the sitting and supine position. J Appl Physiol 1981;51(4):858-863

32. Huang YC, O'Brien SR, MacIntyre NR. Intrabreath diffusing capacity of the lungs in healthy individuals at rest and at exercise. Chest 2002;122(1):177-185.

33. van der Lee I, Zanen P, Grutters JC, Snijder RJ, van den Bosch JM. Diffusing capacity for nitric oxide and carbon monoxide in patients with diffuse parenchymal lung disease and pulmonary arterial hypertension. Chest 2006;129(2):378-383.

34. de Waal EE, Wappler F, Buhre WF. Cardiac output monitoring. Curr Opin Anaesth 2009;22(1):71-77.

35. Kharitonov SA, Barnes PJ. Exhaled biomarkers. Chest 2006;130(5): 1541-1546.

36. Tseliou E, Bessa V, Hillas G, Delimpoura V, Papadaki G, Roussos $\mathrm{C}$, et al. Exhaled nitric oxide and exhaled breath condensate $\mathrm{pH}$ in severe refractory asthma. Chest 2010;138(1):107-113.

37. O'Reilly P, Bailey W. Clinical use of exhaled biomarkers in COPD. Intern J COPD 2007;2(4):403-408.

38. Wagner PD. The multiple inert gas elimination technique (MIGET). Intensive Care Med 2008;34(6):994-1001.

39. Highton D, Elwell C, Smith M. Noninvasive cerebral oximetry: is there light at the end of the tunnel? Curr Opin Anaesth 2010;23(5): 576-581.

40. Elphick HE, Lancaster GA, Solis A, Majumadar A, Gupta R, Smyth RL. Validity and reliability of acoustic analysis of respiratory sounds in infants. Arch Dis Child 2004;89(11):1059-1063.

41. Elphick HE, Ritson S, Rodgers H, Everard ML. When a "wheeze" is not a wheeze: acoustic analysis of breath sounds in infants. Eur Respir J 2000;15:593-597.

42. Muders T, Luepschen H, Putensen C. Impedance tomography as a new monitoring technique. Curr Opin Crit Care 2010;16(3):269-275.

43. Antus B, Barta I, Kullmann T, Lázár Z, Valyon M, Horváth I, Csiszer E. Assessment of exhaled breath condensate $\mathrm{pH}$ in exacerbations of asthma and chronic obstructive pulmonary disease. A longitudinal study. Am J Respir Crit Care Med 2010;182(12):1492-1497.

44. Horváth I, Lázár Z, Gyulai N, Kollai M, Losonczy G. Exhaled biomarkers in lung cancer. Eur Respir J 2009;34(1):261-275.

45. Van Muylem A, Knoop C, Estenne M. Early detection of chronic pulmonary allograft dysfunction by exhaled biomarkers. Am J Respir Care 2007;175(7):731-736.

46. Effros RM. Exhaled breath condensates: delusion or dilution? Chest 2010;138(3):471-472.

\section{Discussion}

Ruppel: Neil, I have a lot of interest in $\mathrm{D}_{\mathrm{LNO}}$, but it occurred to me that, because the NO is taken up in about 4 seconds, we would have to pretty much change the way we do diffusion testing. Do you have any thoughts as to whether that's really practical?

MacIntyre: I only showed it briefly, but when I was showing you my noninvasive cardiac output device, which is a rapid infrared analyzer, that test is done in a matter of seconds. There's no breath-hold required, and I think that methodology could be adapted to NO.

Haynes: Neil, you pointed out that linking our tests to outcomes is very 
important, and I always like to take the opportunity to talk about bronchodilator responsiveness in COPD. Bart Celli and Dennis O'Donnell have been talking about this for years. ${ }^{1}$ Many patients with severe air-flow obstruction and a dynamic airway closure pattern will have no change in $\mathrm{FEV}_{1}$ after bronchodilator. Many clinicians will look at this and say, "The $\mathrm{FEV}_{1}$ doesn't change, so the drugs don't work." What I usually do when I have someone with severe obstruction is include an SVC [slow vital capacity], which better represents dynamic hyperinflation. Often you can see that, even though the $\mathrm{FEV}_{1}$ doesn't change with bronchodilator, the SVC does, indicating that the hyperinflation is amenable to bronchodilator. ${ }^{1}$

1. O’Donnell DE, Forkert L, Webb KA. Evaluation of bronchodilator responses in patients with "irreversible" emphysema. Eur Respir J 2001;18(6):914-920.

MacIntyre: I'll be a little controversial here. Although I'm fascinated with bronchodilator responsiveness and I find it an interesting physiologic parameter, I'm not convinced that bronchodilator responsiveness changes therapy. If you've got somebody like you've described who doesn't change, but has severe airway obstruction and loves their albuterol, the fact that they don't respond to a single whiff of albuterol in the lab doesn't deter me from prescribing albuterol. The flip side is also true: somebody who's perfectly normal comes into the lab and has a $16 \%$ increase in their $\mathrm{FEV}_{1}$ after 4 puffs of albuterol but feels fine and has no symptoms whatsoever-that's not going to force me into prescribing a bronchodilator for them.

Again, I want to keep the physiology and the clinical decision-making concepts separate here. Bronchodilator responsiveness is clearly a very interesting physiologic phenomenon, but in terms of managing patients, I'm not sure how much it adds to our decision-making.

Haynes: I think that it is important how you define bronchodilator responsiveness though, because dynamic hyperinflation, is more closely linked to dyspnea in COPD than the FEV ${ }_{1}$. So if we're going to link our testing to outcomes, we have to choose the test that correlates best with the desired outcome. In the case of COPD the reduction of dynamic hyperinflation, whether you measure it by inspiratory capacity or SVC, correlates best with improvements in dyspnea and quality of life. In severe COPD, relying on $\mathrm{FEV}_{1}$ to guide treatment is an example of not linking testing to outcomes.

Enright: I'd like to be even more controversial, but not on bronchodilator responsiveness, which is a topic I love to hate. Who should be interpreting PFT [pulmonary function test] numbers? I just got back from the Association for Respiratory Technology and Physiology meeting in Glasgow, which is a smaller sister society of the American Association for Respiratory Care. Those who perform PFTs in the United Kingdom are also trained to interpret the results. Perhaps those who interpret PFTs in the United States should take performance-based exams to prove their competence.

MacIntyre: The interpretation of the tests (I touched on it briefly) is problematic. You can take those simple schemes like the ATS/ERS [American Thoracic Society/European Respiratory Society] interpretation algorithm $^{1}$ and plug it into a computer and probably get a fairly decent physiologic classification in probably the majority of patients, but certainly not all of them. The problem a computer has, as I alluded to, is the more subtle stuff: pattern recognition. Is that an effort problem or is it truly an upperairway obstruction? I'm not convinced that the computer will ever be able to do that-well, I'm sure a computer will eventually be able to do it, but certainly not in my lifetime. I think it's going to take skilled pattern-recognition interpreters.

The corollary to this, if I may, is we were in the $\mathrm{NETT}^{2}$ [National Emphysema Treatment Trial] and it took CT [computed tomography] scans and did incredible analyses on them, describing emphysema, patterns of emphysema, distribution of emphysema, and the like. But the one predictor of success with LVRS [lung-volume-reduction surgery] involved CT analysisbut instead of being the computer interpretation it was a simple check box where the radiologist said, "You know, this is upper-lobe predominant emphysema." The check box from the radiologist was a more powerful predictor than all the computerized interpretation of the images. I think the human brain and its pattern-recognition capabilities are, at the moment, still superior to what we've got in the computers. Who knows: that may change some day. Probably will.

1. Pellegrino R, Viegi G, Brusasco V, Crapo RO, Burgos F, Casaburi R, et al. Interpretive strategies for lung function tests. Eur Respir J 2005;26(5):948-968. DOI: 10.1183/09031936.05.00035205

2. Edwards MA, Hazelrigg S, Naunheim KS. The National Emphysema Treatment Trial: summary and update. Thorac Surg Clin 2009;19(2):169-185.

Enright: I'm suggesting that some PFT technologists, such as those at this meeting, could apply the interpretation algorithms better than computers and most of the current batch of medical directors of PFT labs.

Haynes: And many of us do it now for free!

Miller: Paul, you're saying that medical directors of PFT labs, let alone well trained pulmonologists, should not be the ones who interpret PFTs? So if you go to an echocardiography lab and you're a patient, a lot of times as you're walking out the tech will 
say, "You know, you look pretty good, your echo looks normal." You have a CT scan and the technician says "Well, I don't see anything." Do we eliminate the cardiologist or the radiologist? Are we going to be doing the same thing with PFT techs? I think a well trained pulmonologist, just like a well trained cardiologist reading echos, or a well trained hematologist reading bone marrows, is the one to interpret the PFTs.

Enright: Of course, that's the tradition, but I'm saying that the skills of the medical directors of PFT labs have gone down dramatically over the last 20 years, and we don't have a scheme for reversing that downward trend.

Miller: We all have inputs into our training programs, and I think that's where the attention should be. I would say that the 3 [specialists] you cited here are not any more representative of their profession than perhaps we are of ours.

MacIntyre: When the ATS/ERS published that PFT interpretation flowchart, people grabbed it and said "Gee, this is only 6 decision points: anyone can figure that one out." So we may be shooting ourselves in the foot if we make it sound like interpreting PFTs is really easy.

Hnatiuk: I'm not sure I would go so far as to say pulmonologists shouldn't be reading all spirometries or over-reading interpretations from either a computer or from the respiratory care providers. When we looked at internists' spirometric interpretations, they were not that good at it. ${ }^{1} \mathrm{I}$ would support pulmonologists being involved in the interpretations in some way.

1. Hnatiuk O, Moores L, Loughney T, Torrington K. Evaluation of internists' screening spirometry interpretations. J Gen Intern Med 1996;11(4):204-208.
MacIntyre: That's certainly my experience as well. The questions I get are often from the internists, the oncologists, and the surgeons.

Enright: There are about 5,000 hospitals with PFT labs in the United States, and of those, how many signed up for the registry?

MacIntyre: The registry is above 150 but below 200. I can't remember the exact number.

Enright: You might agree that those 200 represent the very best, the ones who are really concerned about learning more about PFTs. I'm worried about the other 4,800 who have medical directors who are generating a lot of income interpreting PFTs with inadequate training and skills. I believe that RPFTs [Registered Pulmonary Function Technologists] could be trained more quickly and more reliably to provide interpretations in those 4,800 labs.

MacIntyre: I know one of the arguments for going to office spirometry — and I've heard this argument-is "Take the spirometer into your office, use it, and you can bill for it, you can interpret it and get whatever the Medicare allowable is," implying again that interpreting it is easy and anybody can do it and bill for it.

Haynes: One of the things that might improve with RPFTs reading tests is the turnaround issue that you talked about. I know in our lab our physicians are very busy and sometimes the pile of tests waiting to be interpreted can be significant. Perhaps some offices get frustrated that they send the patients to get the tests and then have to wait a long time to get the results and maybe some stop sending patients for tests. I've always joked with our pulmonologists, "Why don't you just let me read them and you can co-sign?" I don't advocate that an RPFT would interpret tests without oversight, but there may be a role for RPFT interpretation and having the pulmonary physician sign off on it.

Hnatiuk: I would agree with that. Being in the military for a number of years, we were able to dictate to outside medical centers that we wanted to oversee their quality and have them send us spirometries, and we would give them feedback. The discussion was intriguing for me to hear about this morning, that somebody is moving in that direction to provide accreditation for PFT labs. And perhaps there's a way to do some kind of quality assurance in those centers that you' re talking about: to have them send 100 spirometries to a regional medical center and have them review them and provide feedback.

Kaminsky: The ATS has set up a PFT mentoring program, which is free, and I'm one of the mentors about to start with the program this spring. I think 250 people have signed up so far across the country. These are internists and primary care doctors who are interested in learning more about reading PFTs correctly. They will go through a didactic Web-based session initially, they'll then submit 10 preliminary studies to one of the mentors, whose job will be to review those and give them constructive feedback regarding quality. Then, over a period of a few months, they will submit their tests to the mentor throughout that time and they will be graded on how they do and continue to get constructive feedback. So there are small ways that the societies are trying to improve the quality out there.

Culver: I'm involved in that program, and I'm also doing something similar with a family practice program that's run by a pediatrician in our place, and there are a lot of family practice docs who are interested. Again, they're having tracings sent back in and reviewed on an ongoing basis, so they are trying to close the loop of not just 
sending information out there but to actually provide feedback. And it's tough going. You give a talk and you think you've made some good points, and then you throw up a slide and it's $50 / 50$ whether it's obstructive or restrictive on a really basic spirometry. It's a labor-intensive process.

Hnatiuk: But this is voluntary. Is there any way we can mandate it?

Enright: In the Army!

Culver: Coming back to Paul's suggestion, I have no problem with the best-trained person in the vicinity doing the job. And in some settings it may be the PFT tech or a well trained RT [respiratory therapist]. I think that in those same smaller hospitals we certainly see that in the ICU: who's running the ventilators in there and who's making the decisions about the orders? They may be signed off by a physician, but you know who the physician is getting advice from. Thank heavens that somebody knows what they're doing. Sometimes it's a little scary what some RTs are doing out in the community as well, but it's probably less scary than what some of the physicians who have no experience with ventilators might be doing in those same places. That's a bit of an indictment on the whole medical system, but if we can focus on training people to do the job well, then yes, they should have the opportunity to do it.
MacIntyre: A word of cautionfrom a practical perspective-because I've dealt with CMS [Centers for Medicare and Medicaid Services] and others on this issue. I have no doubt that the technologists and therapists in this room can read PFTs as well as anybody on the planet. The problem is if we start saying that that is reasonable to do, you know what CMS then says: "Well, if you guys can do it, any RT can do it, and if any RT can do it, we're going to pay at the any-RT reimbursement rate." I want to be really cautious in saying that this is something any RT can do. Again, I suspect that you guys - and I think my chief tech is as good at interpreting these things as anybody around-but the third-party payers will lump everybody together, unfortunately, and will assume the worst.

Miller: Neil, what you've said mirrors historical experience. When Medicare stopped using the word "physician" and began using the word "provider," which included lots of nonMDs like nurses and physician assistants, a lot of people in our profession felt that we had been downgraded, and felt a great deal of malaise. Your example is the same type of thing.

MacIntyre: Yeah, and if I can switch to another area, the issue of pulmonary rehab I think is also like this. Most pulmonary rehab programs are run by really good RTs-some- times physical therapists and nurses. And it was obvious that in trying to get a reimbursement code for pulmonary rehab that it was absolutely critical that physician input had to be considered to keep the reimbursement rate at something that was manageable.

Salzman: I'll just add one more comment to this issue of who should interpret. Obviously, this group assembled here are all experts-physicians, PFT technologists, RTs - but my impression is that, while we feel that a lot of pulmonologists are not very well qualified, the current approach of having PFTs interpreted by physicians is probably the best way to do it right now. The future might be different.

Another comment regards some of the educational efforts going on at ATS and ACCP [American College of Chest Physicians] annual meetingsI've been involved in some of this for the last 5-8 years, and we've had annual PFT interpretation sessions, very case-based. These have been very well received and well attended, and I think that's helped to disseminate a very practical approach to PFT education for pulmonologists - of let's throw a bunch of cases up here: not the theoretical stuff, but going through cases. Paul's been involved at the ATS with similar things, and I think that's one good way to get the word out on applying physiologic concepts to better PFT test interpretation. 